\title{
Chemotherapy resistance in metastatic breast cancer: the evolving role of ixabepilone
}

\author{
Edgardo Rivera'* and Henry Gomez ${ }^{2}$
}

\begin{abstract}
Resistance to chemotherapy is a major obstacle to the effective treatment of many tumor types. Although many anticancer therapies can alter tumor growth, in most cases the effect is not long lasting. Consequently, there is a significant need for new agents with low susceptibility to common drug resistance mechanisms in order to improve response rates and potentially extend survival. Approximately $30 \%$ of the women diagnosed with early-stage disease in turn progress to metastatic breast cancer, for which therapeutic options are limited. Current recommendations for first-line chemotherapy include anthracycline-based regimens and taxanes (paclitaxel and docetaxel). They typically give response rates of 30 to $70 \%$ but the responses are often not durable, with a time to progression of 6 to 10 months. Patients with progression or resistance may be administered capecitabine, gemcitabine, vinorelbine, albumin-bound paclitaxel, or ixabepilone, while other drugs are being evaluated. Response rates in this setting tend to be low (20 to 30\%); the median duration of responses is $<6$ months and the results do not always translate into improved longterm outcomes. The present article reviews treatment options in taxane-resistant metastatic breast cancer and the role of ixabepilone in this setting.
\end{abstract}

\section{Introduction}

The development of chemotherapy resistance continues to be the main problem in the treatment of cancer patients. Newer agents, whether chemotherapeutic or targeted, are constantly being developed. Although most anticancer therapies will alter tumor growth, in most cases the effect is not long lasting and failure of

*Correspondence: erivera1@tmhs.org

'The Methodist Hospital/Weill Cornell University, 6550 Fannin Street, SM701,

Houston, TX 77030, USA

Full list of author information is available at the end of the article anthracyclines and taxanes impact the survival of breast cancer patients. Consequently, there is a significant need for new agents with low susceptibility to common drug resistance mechanisms in order to improve response rates and potentially extend survival.

Approximately $30 \%$ of the women diagnosed with early-stage disease in turn progress to metastatic breast cancer (MBC), for which therapeutic options are limited [1]. After treatment with anthracycline or taxane-based [2] chemotherapy, options are limited as responses are generally low. Response rates range from 30\% to $70 \%$ but the responses are often not durable, with a time to progression of 6 to 10 months [1,3]. Patients with progression or resistance may be administered capecitabine, gemcitabine, vinorelbine, or albumin-bound paclitaxel, with capecitabine being the only one approved by the US Food and Drug Administration (FDA) after anthracyclines and taxanes $[4,5]$. Response rates in this setting tend to be low (20 to $30 \%$ ); the median duration of responses is $<6$ months [6] and the results do not always translate into improved long-term outcomes.

Resistance to chemotherapy can occur prior to drug treatment (primary or innate resistance) or may develop over time following exposure (acquired resistance) [7]. Patients with breast cancer who are treated with an anthracycline and/or a taxane commonly develop resistance to one or both of the drugs. In some patients, prolonged exposure to a single chemotherapeutic agent may lead to the development of resistance to multiple other structurally unrelated compounds, known as crossresistance or multidrug resistance (MDR). In primary resistance, MDR can occur without prior exposure to chemotherapy.

Once resistance to taxanes or anthracyclines occurs, few treatment options exist. Most breast cancer patients with resistant or refractory disease are treated with capecitabine as a single agent or in combination. Approximately $75 \%$ of patients treated with capecitabine do not respond, and many responders eventually become resistant [8-10]. Other chemotherapeutics that are used for the treatment of MBC resistant to anthracyclines, taxanes, and capecitabine include gemcitabine and vinorelbine [11]. Response rates with these agents in 
anthracycline-refractory and taxane-refractory disease range from 16 to $25 \%$, and survival is limited [1,12-14]. Resistance is also an issue for women who have human epidermal growth factor receptor-2 (HER2)-positive breast cancer. The HER2-specific inhibitors trastuzumab and lapatinib have demonstrated efficacy in the metastatic setting [15-17]. Most MBC patients treated with trastuzumab, however, develop resistance within 1 year [18].

Recent research has suggested potential novel therapeutic targets for drug-resistant MBC. Tumor stem cells have been identified in many malignancies, including breast cancer $[19,20]$. Accumulation of drug resistance mutations in stem cells, coupled with their highlevel expression of the ATP-binding cassette $(\mathrm{ABC})$ drug transporters, noncycling state, and enhanced DNA repair, may contribute to the generation of resistance to chemotherapy [21]. The high proliferative potential of such cells could therefore result in the rapid regrowth of resistant tumors. Studies are currently investigating the potential to specifically target breast cancer stem cells using agents that block drug transport or other smallmolecule inhibitors [20]. It has been proposed that drug resistance may develop early in tumorigenesis, prior to the onset of well-recognized genotypic changes. Targeting initial events in tumorigenesis may suppress the early development of drug resistance. Novel microtubule inhibitors, such as ixabepilone, show significant activity in $\mathrm{MBC}$ and do not exhibit cross-resistance with taxanes or other commonly used chemotherapies; they are therefore potential candidates for the treatment of drugresistant diseases $[22,23]$.

The aim of the present article is to review the current therapeutic alternatives to treat $\mathrm{MBC}$ resistant to taxanes.

\section{Molecular mechanisms of drug resistance}

Chemotherapy resistance can arise through a number of different mechanisms, including alterations in drug pharmacokinetics and metabolism, modification of drug target expression or function (for example, gene amplification/overexpression, overexpression of $\beta$-tubulin isotypes, and topoisomerase II mutations), drug compartmentalization in cellular organelles, altered repair of druginduced DNA damage, changes in apoptotic signaling pathways (for example, mutated p53), and expression of proteins directly affecting cellular drug transport (efflux pumps) (Table 1) $[24,25]$. The heterogeneity of cancer cells, coupled with their high mutation rate, contributes to rapid selection for drug-resistant clones. The best characterized of these resistance mechanisms are drug efflux pathways.

Many transport-mediated drug resistance mechanisms involve the $\mathrm{ABC}$ membrane transporter family. The most well-characterized examples of these drug efflux transporters include the P-glycoprotein (P-gp) pump, multidrug-resistant protein-1 (MRP1), and breast cancer resistance protein. These energy-dependent proteins actively pump drugs such as chemotherapeutics out of the cells, thereby reducing their intracellular drug concentration and decreasing the cytotoxicity [7].

\section{Drug transport/sequestration}

Expression of pumps such as P-gp or MRP1 gives tumor cells the ability to evade the chemotherapy drugs, and their role has been evaluated in breast cancer.

P-gp is a $170 \mathrm{kDa}$ glycoprotein encoded by the MDR1 gene. This ATP-dependent membrane transporter pumps a diverse array of chemotherapeutics across the cell membrane and out of the cells, including anthracyclines, taxanes, vinca alkaloids, epipodophyllotoxins, and antifolates. The normal physiologic role of P-gp is still unknown, but it may serve to protect normal tissues from toxic products and xenobiotics [24]. P-gp expression varies widely in breast cancer, according to the assay method used. A meta-analysis revealed that this protein is expressed in approximately $40 \%$ of all breast carcinomas [26], although another study reported values as high as 66\% [27]. Exposure to selected chemotherapeutics may increase P-gp expression in breast cancer, as seen in some patients following neoadjuvant chemotherapy $[28,29]$. In the meta-analysis, prior chemotherapy or hormonal therapy was found to enhance the proportion of P-gp-positive tumors by nearly 1.8 -fold. This increased P-gp expression was associated with a threefold increased risk of failure to respond to chemotherapy [26]. The expression of P-gp, therefore, correlated with a poorer outcome in this and other studies [30,31], although other reports did not find such an association [27,32].

MRP1 has been also implicated in MDR. MRP1 belongs to the $\mathrm{ABC}$ drug transporter family, included with seven known members (MRP1 to MRP7), which all differ in tissue distribution and drug transport specificity [33]. As determined by RT-PCR, MRP1 is expressed in nearly all breast cancers (and in approximately one-half of normal breast tissues) [25]. This protein confers an MDR phenotype similar to, but distinct from, that associated with P-gp. MRP1 mediates resistance to agents such as vinca alkaloids, anthracyclines, and high-dose methotrexate, but not to paclitaxel or mitoxantrone. Some studies suggest that MRP1 expression correlates with poor survival in patients with early-stage disease who received chemotherapy, although a causal relationship is not clear [34].

Another $\mathrm{ABC}$ membrane transporter that may play a role in drug resistance is breast cancer resistance protein, since it is involved with the efflux of various chemotherapeutics such as mitoxantrone, anthracyclines, methotrexate, and topoisomerase I inhibitors [35]. Resistance mediated by breast cancer resistance protein 
Table 1. Mechanisms of drug resistance in breast cancer $[24,25]$

\begin{tabular}{|c|c|}
\hline Class of resistance & Drug examples \\
\hline Drug transport/sequestration & ABC transporters: P-glycoprotein, multidrug-resistant protein 1 (breast cancer resistance protein) \\
\hline Modification of drug target (qualitative and quantitative) & Dihydrofolate reductase, epidermal growth factor receptor; C-KIT mutations; tubulin \\
\hline DNA repair/genomic instability & $\begin{array}{l}\text { Mismatch repair proteins; caspases, PTEN; p27; microsatellite instability, loss of heterozygosity, } \\
\text { topoisomerase I, topoisomerase II }\end{array}$ \\
\hline Regulators of apoptosis & p53; PTEN; BCl-2, Bcl-x \\
\hline Drug metabolism/inactivation & Cytochrome P450; glutathione S-transferase; aldehyde dehydrogenase \\
\hline
\end{tabular}

ABC, ATP-binding cassette; PTEN, phosphatase and tensin homolog deleted on chromosome 10.

is similar to the pattern seen with P-gp-mediated chemoresistance. This transporter may be a marker for tumor stem cells and appears to protect against hypoxia [36,37].

\section{Modification of drug target}

Microtubules are essential components of the cytoskeleton and mitotic apparatus. They are assembled from $\alpha$-tubulin and $\beta$-tubulin heterodimers, along with other proteins such as microtubule-associated proteins. Microtubule-targeting agents both inhibit microtubule polymerization and destabilize microtubules (such as vinca alkaloids), or they promote their polymerization and stabilization (for example, taxanes) [38]. Paclitaxel is known to bind to BIII-tubulin, which is one of the six known $\beta$-tubulin isotypes. Binding disrupts the microtubule dynamics by stabilizing microtubules and inducing microtubule bundles, thereby inhibiting cell division and triggering apoptosis [38].

Altered expression of $\beta$-tubulin isotypes is found in many cancer cell lines and xenografts resistant to microtubule inhibitors, and this may be associated with the primary or acquired resistance to tubulin-binding agents observed clinically in many tumors (alterations in tubulin and associated proteins can affect the microtubule structure and function, and have been implicated in drug resistance; see Table 2) [39-47]. In vitro, the overexpression of the BIII subunit induces paclitaxel resistance, possibly by decreasing paclitaxel's binding to $\beta I I I-t u b u l i n$ and disrupting the microtubule dynamics [42]. This phenotype was seen in a leukemia cell line that was resistant to vinblastine, which was also cross-resistant to other vinca alkaloids and paclitaxel [48]. Other studies have also observed altered expression levels of tubulin or BIII isoforms that are associated with taxane resistance $[40,41]$. Additionally, several $\beta$-tubulin mutations have been characterized that result in drug resistance [43-45], which is probably due to alterations affecting the drug-binding sites. Owing to the confounding presence of tubulin pseudogenes, however, the clinical significance of these mutations is unclear [49]. Changes in microtubule-associated proteins, such as microtubule-associated protein- 4 and tau, can also affect the microtubule dynamics and modulate sensitivity to taxanes and vincas $[46,47]$.

\section{Table 2. Role of $\beta$-tubulin in drug resistance}

Altered expression of $\beta$-tubulin isotypes $[41,42]$

Overexpression of the $\beta I I-$-tubulin subunit $[40,43]$

$\beta$-Tubulin mutations affecting microtubule stability and the binding of microtubule inhibitors [44-46]

Changes in microtubule-associated proteins (for example, tau and microtubule-associated protein-4) $[47,48]$

Post-translational modifications of tubulin (for example, acetylation) [40]

Clinically, $\beta I I I$ overexpression may serve as a surrogate for paclitaxel resistance in advanced breast cancer [50]. In breast cancer patients who are treated with first-line paclitaxel, high $\beta$ III-tubulin expression correlated with disease progression [51]; similar results were seen in paclitaxel-resistant ovarian cancer [52].

\section{DNA repair and cellular damage}

In addition to P-gp and $\beta$-tubulin alterations, other mechanisms have been implicated in breast cancer drug resistance. Alterations in enzymes that are involved in DNA repair or that affect drug sensitivity can also affect drug resistance. Topoisomerase II is a critical enzyme that is involved in DNA replication and repair, in which reduced topoisomerase II expression or function can contribute to resistance to agents such as anthracyclines and epipodophyllotoxins [7,53]. The loss of DNAmismatch repair activity - which mediates damage repair from many drugs including alkylating agents, platinum compounds, and anthracyclines - has also been implicated in drug resistance [54]. In breast cancer, altered DNA-mismatch repair is associated with microsatellite instability. The loss of function of the DNA-mismatch repair proteins $\mathrm{MSH} 2$ and $\mathrm{MLH} 1$ resulted in resistance to the topoisomerase II inhibitors epirubicin, doxorubicin, and mitoxantrone, but not to taxanes [55]. The reduced expression of MLH1, following neoadjuvant chemotherapy for node-positive breast cancer, predicted poor disease-free survival [56], and in a study of sporadic invasive ductal carcinoma it was associated with resistance to the adjuvant cyclophosphamide, methotrexate, and fluorouracil [57]. In general, the loss of heterozygosity or microsatellite instability can contribute 
to tumor progression and may be associated with resistance to certain regimens, such as epirubicincyclophosphamide-based chemotherapy [58].

\section{Apoptosis}

In addition to DNA-mismatch repair, alterations regulating cellular damage can contribute to drug resistance. The levels of the thiol protease caspase-3, a key mediator of apoptosis, were found to be significantly higher in breast cancer compared with normal tissue [59]. The expression of a caspase-3s splice variant was also higher in breast carcinomas compared with nontumor tissue, and increased levels were correlated with resistance to cyclophosphamide-containing chemotherapy [60].

MDR can arise from a failure of the cells to undergo apoptosis following DNA damage or other cellular injury. Mutations in the p53 tumor suppressor gene (which regulates apoptosis) are found in most human breast cancer cell lines [61], and certain mutations have been linked to de novo resistance to doxorubicin and early relapse in breast cancer [62]. In one study, $p 53$ mutations were a strong prognostic factor for survival in patients with node-positive breast cancer who were administered adjuvant cyclophosphamide, methotrexate, and fluorouracil, which may therefore predict resistance to such therapy [63]. Alterations in other genes regulating the apoptotic pathway, such as $b c l-2$ and $b c l-x$, may also promote resistance to tubulin inhibitors [64]. The tumor suppressors phosphatase and tensin homolog deleted on chromosome 10 and p27 both regulate apoptosis, and the decreased expression of these proteins has been proposed to affect the response to trastuzumab [65] and resistance to chemotherapy [66], respectively.

\section{Drug inactivation/detoxification}

Other enzymes may affect breast cancer drug resistance, including those regulating drug inactivation or detoxification. Isoforms of aldehyde dehydrogenase, such as ALDH1A1 and ALDH3A1, can catalyze the detoxification of cyclophosphamide and may therefore reduce sensitivity to this agent. Higher levels of ALDH3A1 have been found in breast cancer cells compared with normal tissues [67]. Moreover, the cellular levels of ALDH1A1 (but not ALDH3A1) were significantly higher in those metastatic tumors that did not respond to cyclophosphamide-based regimens, when compared with tumors that were sensitive. Glutathione and glutathione S-transferase are involved in the detoxification of alkylating agents and cisplatin, so the modulation of their activity might affect the resistance to these compounds [68]. Cytochrome p450 is another enzyme that could be involved in resistance in taxanes. Polymorphisms in CYP3A4 and CYP2C8 associated with greater basal enzymatic activity lead to reduced plasma concentrations of the active drug [69].

\section{Capecitabine}

Capecitabine (fluoropyrimidine carbamate) is rationally designed to generate fluorouracil preferentially in tumor tissue and to mimic continuous infusion of fluorouracil. Capecitabine is hydrolyzed in the liver by the enzyme carboxylesterase to produce 5 ' -deoxy-5-fluorocytidine, is then deaminated on its pyrimidine ring to produce 5 '-deoxy-5-fluorouridine by the enzyme cytidine deaminase, located mainly in hepatic and neoplastic tissue, and finally thymidine phosphorylase produces activation of $5^{\prime}$-deoxy-5-fluorouridine to fluorouracil in tumor cells, thus minimizing systemic exposure to fluorouracil [70].

Nowadays, capecitabine is the agent most evaluated in patients treated with taxanes. Clinical evidence supports the use of capecitabine in patients with MBC who have been previously exposed to taxanes. The first trial to evaluate the efficacy and safety of capecitabine (twicedaily oral $2,510 \mathrm{mg} / \mathrm{m}^{2} /$ day for 2 weeks followed by a 1 -week rest and repeated in 3-week cycles) on 162 patients with paclitaxel refractory $\mathrm{MBC}$ observed an overall response rate of $20 \%$ (95\% confidence interval (CI), 14 to $28 \%$ ) [71]. Diarrhea (14\%) and hand-foot syndrome $(10 \%)$ were the only treatment-related adverse events that occurred with grade 3 or grade 4 intensity in more than $10 \%$ of patients [71]. In a posterior phase II trial with 74 patients, an overall response rate of $26 \%$, a median survival of 12.2 months, a median duration of response of 8.3 months, and a median time to disease progression of 3.2 months were observed [8]. With regard to the safety, treatment was well tolerated and the only grade 3 treatment-related adverse events reported in $\geq 10 \%$ of patients were hand-foot syndrome (22\%), diarrhea (16\%), and stomatitis (12\%) [8]. Other trials have also proven the efficacy of capecitabine $[9,10]$.

\section{Epothilones}

Given the clinical significance of drug resistance found in most tumor cells and the challenges this presents for cancer therapy, new agents with novel mechanisms of action are needed. Epothilones represent a new class of microtubule inhibitors that have shown promising activity in MDR tumor cells, and have therefore been explored for the treatment of drug-resistant $\mathrm{MBC}$.

Epothilones are a family of naturally occurring cytotoxic macrolides that inhibit microtubule function. Epothilones A and B, which are two major fermentation products originally isolated from the broth of the myxobacterium Sorangium cellulosum, were found to stabilize polymerized microtubules and therefore to inhibit depolymerization [72,73]. The epothilones are 
structurally different from paclitaxel and docetaxel and may have a distinct mechanism of action [3]. Structural analyses indicate that epothilones may bind at or near the paclitaxel binding site on the $\beta$-tubulin protein [74-76]. In contrast to taxanes, certain epothilone $B$ analogs inhibit those drug-resistant cells that overexpress P-gp suggesting these compounds may be effective for the treatment of drug-resistant tumors, including those with an MDR phenotype.

\section{Ixabepilone}

One of the most active epothilone analogs is the semisynthetic derivative ixabepilone, which has superior stability and water solubility compared with epothilone B [77]. Just as in paclitaxel, ixabepilone results in $\mathrm{G}_{2} / \mathrm{M}$ cell cycle arrest and subsequent apoptosis, yet its median inhibitory concentration value is approximately 1 log lower than this taxane [23]. Low nanomolar concentrations of ixabepilone exert broad antitumor activity in a variety of solid tumor cell lines, including breast carcinoma [22,23]. In contrast to paclitaxel, ixabepilone can bind to multiple isomers of $\beta$-tubulin, including the $\beta I I I$ isoform [78].

In vitro, ixabepilone inhibits the growth of several drug-resistant cell lines, including some that are resistant to paclitaxel (Table 3) [11,22,23,78-80]. Ixabepilone has low susceptibility to various drug resistance mechanisms, such as MDR overexpression [81], $\beta$-tubulin mutations [82], and the overexpression of the $\beta$ III-tubulin isotype $[22,77,83]$. Notably, ixabepilone has shown activity in breast cancers with primary and acquired taxane resistance. Ixabepilone is not a good substrate for MDR and does not strongly induce P-gp expression (possibly because of the relatively flexible structure of this compound), which may in part account for its activity in drug-resistant tumors [11]. Ixabepilone is not only active against paclitaxel-sensitive xenografts, but also demonstrates significant activity with paclitaxel-resistant human tumor models including breast carcinoma, ovarian cancer, and colorectal cancer xenografts [22].

In addition to showing activity in breast cancer, ixabepilone has also shown activity against a variety of other solid tumors. Antitumor activity was noted in cancers that were heavily pretreated or refractory, including platinum-refractory nonsmall-cell lung cancer [84]. Ixabepilone has demonstrated clinical activity in some patients with tumors that are considered chemotherapy resistant, such as renal cell carcinoma [85] and advanced pancreatic cancer [86]. In light of its activity in breast cancer, and particularly in drug-resistant tumors, the clinical activity of ixabepilone was evaluated in patients with drug-resistant $\mathrm{MBC}$.

As discussed previously, alterations in $\beta$-tubulin expression (including the $\beta$ III isotype) are associated with clinical resistance to taxanes. In contrast to paclitaxel,
Table 3. Preclinical activity of ixabepilone in drug-resistant cancer

Active against numerous drug-resistant tumor cell lines, including human

paclitaxel-resistant breast cancer cell lines and xenografts [23,76-78]

Inhibitory activity in breast cancers with primary or acquired resistance $[23,78]$

Low susceptibility to multiple mechanisms of drug resistance $[23,76]$

Multidrug resistance overexpression: overexpression of the $\beta 11$-tubulin isotype

Poor substrate for multidrug resistance; does not strongly induce P-glycoprotein expression [12]

ixabepilone can bind to $\beta$ III-tubulin-containing microtubules, which are dynamically more unstable than $\beta I I-$ tubulin-based microtubules [78]. In addition, ixabepilone is active in preclinical tumor models that are resistant to paclitaxel due to mutations in $\beta$-tubulin $[22,43]$. Together, these results suggest that ixabepilone is effective for the treatment of breast cancer that is resistant to taxanes and to other agents arising from a variety of mechanisms. Molecular mechanisms of resistance to ixabepilone are still unknown and there have been no studies with a representative number of patients, but is suggested that polymorphisms of the carboxyl terminus of class I $\beta$-tubulin could be linked to resistance [87].

\section{Clinical evidence of efficacy of ixabepilone in drug- resistant metastatic breast cancer}

Four key clinical trials of ixabepilone in drug-resistant breast cancer have been conducted, including two studies with single-agent ixabepilone and two studies with ixabepilone combined with capecitabine (Table 4) [88-92]. The results of these studies indicate that ixabepilone is active in patients with a pretreated disease, including tumors resistant to anthracyclines, taxanes, and capecitabine, and in patients with widespread metastatic disease.

\section{Taxane-resistant MBC: Trial 009}

Given its activity in taxane-resistant breast cancer models, ixabepilone was clinically evaluated in patients with $\mathrm{MBC}$ resistant to taxane therapy. An international, multicenter phase II trial evaluated single-agent ixabepilone in patients with $\mathrm{MBC}$ who were previously treated with an anthracycline-based regimen and were resistant to a taxane [88]. Patients were eligible if they had progressed within 4 months of taxane therapy in the metastatic setting (6 months if treated with adjuvant therapy only) and had a taxane as their last chemotherapy regimen. Consequently, these tumors were highly resistant to prior treatment with a microtubule-stabilizing agent. Forty-nine patients were administered ixabepilone $40 \mathrm{mg} / \mathrm{m}^{2}$, infused over 3 hours, every 21 days for up to 
Table 4. Clinical trials of ixabepilone in drug-resistant metastatic breast cancer

\begin{tabular}{|c|c|c|c|c|}
\hline Study & Population & $\begin{array}{l}\text { luable for } \\
\text { acy/enrolled }\end{array}$ & Pretreatment characteristics & Activity \\
\hline \multicolumn{5}{|c|}{ Ixabepilone monotherapy } \\
\hline $\begin{array}{l}\text { Trial 009, phase II } \\
\text { [88] }\end{array}$ & $\begin{array}{l}\text { Resistant to taxane; prior } \\
\text { treatment with anthracycline- } \\
\text { based regimen }{ }^{\mathrm{a}}\end{array}$ & $49 / 49$ & $\begin{array}{l}\text { All had received } \geq 1 \text { prior taxane-based regimen } \\
\text { ( } 31 \% \text { had } \geq 2 \text { regimens); } 98 \% \text { had a taxane- } \\
\text { containing regimen as their most recent MBC } \\
\text { therapy, and } 73 \% \text { had progressed within } 1 \text { month } \\
\text { of the last administered taxane dose }\end{array}$ & $\begin{array}{l}\text { ORR 12\%; } 41 \% \text { stable disease } \\
\text { Median DOR } 10.4 \text { months } \\
\text { Median TTP } 2.2 \text { months } \\
\text { (95\% Cl, } 1.4 \text { to } 3.2 \text { months) } \\
\text { Median OS } 7.9 \text { months } \\
\text { (95\% Cl, } 6.1 \text { to } 14.5 \text { months) }\end{array}$ \\
\hline $\begin{array}{l}\text { Trial 081, phase II } \\
\text { [89] }\end{array}$ & $\begin{array}{l}\text { Resistant to an anthracycline, } \\
\text { a taxane, and capecitabine }\end{array}$ & $113 / 126$ & $\begin{array}{l}77 \% \text { with visceral disease in liver and/or lung; } \\
88 \% \text { had completed } \geq 2 \text { prior chemotherapy } \\
\text { regimens for } M B C, 48 \% \text { had } \geq 3 \text { lines }\end{array}$ & $\begin{array}{l}\text { ORR 11.5\%; } 50 \% \text { stable disease } \\
\text { Median DOR } 5.7 \text { months } \\
\text { (95\% Cl, } 4.4 \text { to } 7.3 \text { months) } \\
\text { Median PFS } 3.1 \text { months } \\
\text { (95\% Cl, } 2.7 \text { to } 4.2 \text { months) } \\
\text { Median OS } 8.6 \text { months } \\
\text { (95\% Cl, } 6.9 \text { to } 11.1 \text { months) }\end{array}$ \\
\hline \multicolumn{5}{|c|}{ Ixabepilone/capecitabine combination } \\
\hline $\begin{array}{l}\text { Trial 031, phase II } \\
\text { [90] }\end{array}$ & $\begin{array}{l}\text { Anthracycline-pretreated } \\
\text { or resistant and taxane- } \\
\text { resistant }^{\text {b }}\end{array}$ & $50 / 62$ & $\begin{array}{l}72 \% \text { had baseline visceral metastases, } 43 \% \\
\text { had } \geq 2 \text { prior chemotherapy regimens in the } \\
\text { metastatic setting for MBC }\end{array}$ & $\begin{array}{l}\text { ORR } 30 \% \text {; } 32 \% \text { stable disease } \\
\text { Median time to response } \\
6 \text { weeks (range, } 5 \text { to } 14 \text { weeks) } \\
\text { Median DOR } 6.9 \text { months } \\
\text { (95\% Cl, } 4.3 \text { to } 9.7 \text { months) }\end{array}$ \\
\hline $\begin{array}{l}\text { Trial 046, phase III } \\
\text { [92] }\end{array}$ & $\begin{array}{l}\text { Pretreated with or resistant } \\
\text { to anthracyclines and } \\
\text { resistant to taxanes }\end{array}$ & $737 / 752$ & $\begin{array}{l}65 \% \text { had } \geq 3 \text { metastatic disease sites; } 48 \% \text { had } \\
\text { received } \geq 1 \text { prior regimen for MBC; } 85 \% \text { had } \\
\text { progressed on prior taxane therapy for } \\
\text { metastatic disease }\end{array}$ & $\begin{array}{l}\text { ORR } 34.7 \% \text { vs. } 14.3 \% \\
\text { Median DOR } 6.4 \text { months vs. } \\
5.6 \text { months } \\
\text { Median PFS } 5.8 \text { months vs. } \\
4.2 \text { months; hazard ratio }=0.75 \\
(95 \% \mathrm{Cl}, 0.64 \text { to } 0.88)^{\mathrm{e}}\end{array}$ \\
\hline
\end{tabular}

MBC, metastatic breast cancer; ORR, overall response rate; DOR, duration of response; TTP, time to progression (months); Cl, confidence interval; OS, overall survival; PFS, progression-free survival. aPatients had progressed within 4 months of taxane therapy ( 6 months, if adjuvant therapy only) and had a taxane as their last chemotherapy regimen. ${ }^{\mathrm{b}}$ Patients were ineligible if they had received more than three prior chemotherapy regimens for metastatic disease. ${ }^{\mathrm{A}} \mathrm{All}$ responders had extensive metastatic disease at baseline. ${ }^{\mathrm{d}}$ Resistance to anthracycline and taxane is defined as tumor progression during treatment or within 3 months of the last administered dose in the metastatic setting, or recurrence within 6 months in the neoadjuvant or adjuvant setting. This was subsequently revised to include recurrence within 4 months of the last administered dose in the metastatic setting or 12 months in an adjuvant setting. ${ }^{e} P=0.0003$.

18 cycles due to progressive disease. The overall response rate (ORR) was the primary endpoint.

Most patients in this study had been treated with at least two prior chemotherapy regimens. All of the patients had received at least one prior taxane-containing regimen ( $31 \%$ had at least two regimens), and $98 \%$ of patients had a taxane-containing regimen as their most recent therapy in the metastatic setting. This population was highly refractory because $73 \%$ of the patients had progressed within 1 month of their last administered taxane dose.

Of the 49 patients eligible for efficacy analysis, there were six responses (ORR 12\%) with a median duration of response of 10.4 months. All of the responders had extensive baseline disease and had failed multiple therapies.
An additional 20 patients (41\%) had stable disease as their best response. The median time to progression was 2.2 months ( $95 \% \mathrm{CI}, 1.4$ to 3.2 months), and the median survival was 7.9 months (95\% CI, 6.1 to 14.5 months). Responses seen with ixabepilone in patients with taxaneresistant $\mathrm{MBC}$ confirm its clinical activity in this patient population and support its differential sensitivity to the mechanisms of resistance.

\section{Anthracycline-resistant, taxane-resistant, and capecitabine-resistant MBC: Trial 081}

The largest phase II trial evaluated single-agent ixabepilone in patients with heavily pretreated or locally advanced disease or MBC resistant to the three standard chemotherapeutics in this setting; that is, anthracyclines, 
taxanes, and capecitabine [89]. Resistance to each drug class was defined as disease progression during therapy for MBC ( $\leq 8$ weeks of the previous treatment) or disease recurrence within 6 months of adjuvant or neoadjuvant chemotherapy with anthracycline or taxane. Ixabepilone $40 \mathrm{mg} / \mathrm{m}^{2}$ was administered as a 3-hour intravenous infusion on day 1 of a 21-day cycle. The primary study endpoint was the ORR.

The patients in this study had significant and widespread baseline disease: visceral disease in the liver and/ or lung was present in $77 \%$ of patients, and more than $40 \%$ had at least three target lesions. The majority of the patients $(88 \%)$ had completed at least two prior chemotherapy regimens for $\mathrm{MBC}$, and $48 \%$ had at least three therapy lines; $15 \%$ and $30 \%$ of patients had at least one line of anthracycline therapy and taxane therapy, respectively. All but two treated patients had taxaneresistant disease, while $38 \%$ had anthracycline-resistant tumors. Many had failed prior chemotherapy for MBC including vinorelbine (25\%), gemcitabine (13\%), and trastuzumab for HER2-positive disease (9\%).

Of the 126 patients enrolled, 113 were evaluable for a response. As assessed independently, the ORR was $11.5 \%$ (all partial responses) with another $50 \%$ of the patients achieving stable disease as their best response. Tumor responses were durable, with a median duration of 5.7 months (95\% CI, 4.4 to 7.3 months); eight of the 13 responders remained progression free for $\geq 6$ months. The median progression-free survival (PFS) was 3.1 months (95\% CI, 2.7 to 4.2 months), and the median overall survival was 8.6 months $(95 \% \mathrm{CI}, 6.9$ to 11.1 months). Ixabepilone monotherapy was therefore active in patients with difficult-to-treat, advanced, highly refractory breast cancer who had failed to respond to prior chemotherapy. One should note that nine of the 12 responders to ixabepilone had not responded to prior multiple lines of chemotherapy in the metastatic setting, including combination regimens.

Anthracycline-resistant and taxane-resistant MBC: Trial 031 Given the single-agent activity of ixabepilone in women previously treated with anthracyclines, taxanes, and capecitabine, and the need for more effective second-line $\mathrm{MBC}$ regimens, the combination of ixabepilone and capecitabine was evaluated in phase II and phase III trials. In the phase II study, patients previously treated with anthracyclines and taxanes were treated with ixabepilone in addition to capecitabine [90]. Sixty-two patients were administered ixabepilone $40 \mathrm{mg} / \mathrm{m}^{2}$, infused over 3 hours on day 1 , in addition to capecitabine $2,000 \mathrm{mg} / \mathrm{m}^{2}$ on days 1 to 14 , both given every 21 days. Patients were ineligible if they had received more than three prior chemotherapy regimens for metastatic disease.
Fifty patients were evaluable for a response: $72 \%$ had baseline visceral metastases, and $42 \%$ received at least two prior chemotherapy regimens for metastatic disease. Fifteen responses occurred (30\% ORR), and stable disease was achieved in $32 \%$ of patients. All of the responders had extensive metastatic disease at baseline. The median time to response was 6 weeks (range, 5 to 14 weeks), with most responses occurring by the end of the second cycle. The median duration of response was 6.9 months (95\% CI, 4.3 to 9.7 months). Four of the 15 responses occurred in patients with estrogen receptor-negative, progesterone receptor-negative, and HER2-negative (triple-negative) breast cancer, suggesting such a regimen may be effective for patients with this treatment-resistant subtype [91]. These preliminary results indicated that the combination of ixabepilone and capecitabine is active in patients with anthracycline-resistant and taxane-resistant MBC.

\section{Anthracycline-resistant and taxane-resistant MBC: Trial 046} These encouraging phase II results led to an international, randomized, open-label phase III trial that compared ixabepilone plus capecitabine with solely capecitabine administration in patients with locally advanced or MBC pretreated with or resistant to anthracyclines and taxanes [92]. Patients were treated with ixabepilone $40 \mathrm{mg} / \mathrm{m}^{2}$, administered as a 3-hour infusion on day 1 of a 21-day cycle, plus capecitabine $2,000 \mathrm{mg} / \mathrm{m}^{2}$ on days 1 to 14 of a 21-day cycle. Those patients on capecitabine alone were administered a dose of $2,500 \mathrm{mg} / \mathrm{m}^{2}$ on days 1 to 14 of a 21-day cycle. The primary endpoint was PFS. The patients enrolled in this study $(n=752)$ had widespread disease and were heavily pretreated with chemotherapy. Most patients (65\%) had at least three metastatic disease sites, and nearly one-half had received at least two prior regimens for metastatic disease. The majority of patients (85\%) had progressed on prior taxane therapy for MBC.

The trial results demonstrated that PFS significantly improved for patients treated with ixabepilone plus capecitabine compared with capecitabine alone (hazard ratio, $0.75 ; 95 \% \mathrm{CI}, 0.64$ to $0.88 ; P=0.0003$ ), in turn reflecting a $25 \%$ reduction in the estimated risk of disease progression (Figure 1). Median PFS increased by $40 \%$ with the combination (5.8 months vs. 4.2 months). Subset analyses indicated that the PFS benefit occurred across subgroups. The ORR also significantly increased in the ixabepilone/capecitabine arm $(35 \% ; P<0.0001)$ compared with capecitabine alone (14\%); stable disease occurred in $41 \%$ and $46 \%$ of patients, respectively. The combination regimen demonstrated activity in triple-negative disease, confirming the activity observed in this subgroup in the phase II trial. Mature overall survival data are anticipated within several months. The most frequent grade $3 / 4$ adverse events in the ixabepilone plus capecitabine group were peripheral sensory neuropathy (with a median onset 


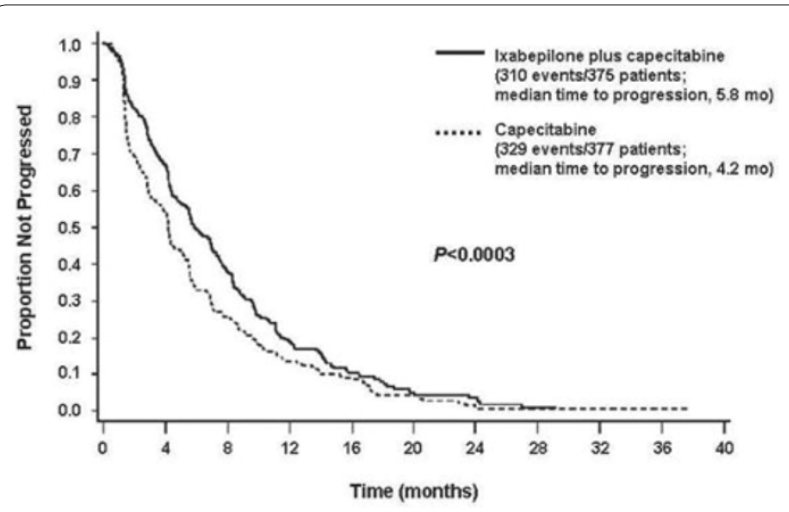

Figure 1. Progression-free survival for patients treated with ixabepilone plus capecitabine. Kaplan-Meier progression-free survival curve from a phase III trial of ixabepilone plus capecitabine for metastatic breast cancer patients progressing after anthracycline and taxane treatment [88]. Reprinted with permission from Journal of Clinical Oncology.

of four cycles), hand-foot syndrome, fatigue, myalgia, asthenia, and diarrhea; while the most frequent grade $3 / 4$ adverse events in the capecitabine group were hand-foot syndrome and diarrhea, but with incidences similar to those for the combination arm. The incidence of adverse events commonly associated with capecitabine, such as hand-foot syndrome, were not exacerbated by the addition of ixabepilone.

\section{Other metastatic breast cancer patient populations}

In addition to its efficacy in breast cancer resistant to chemotherapy, ixabepilone may also be effective for the treatment of other difficult-to-treat populations. A prospective subset analysis of the above phase III trial evaluated the response in HER2-positive patients who had been pretreated with or were resistant to anthracyclines and taxanes, and who had progressed on trastuzumab [93]. The combination of ixabepilone and capecitabine significantly prolonged median PFS (5.3 months vs. 4.1 months) and the ORR (31\% vs. $8 \%$ ) compared with capecitabine monotherapy, which is similar to the benefit observed in the overall population.

In a phase II trial, ixabepilone was combined with trastuzumab and carboplatin in patients with HER2positive MBC [94]. Of the 57 patients evaluable for a response, two had complete responses (3.5\%), 22 had partial responses (38.6\%), and 13 had stable disease for $>6$ months (22.8\%); the median PFS was 8 months. A second prospectively defined subgroup analysis of the phase III study evaluated the combination regimen in patients with anthracycline-pretreated or anthracycline-resistant MBC whose tumors were estrogen receptor-negative [95]. Ixabepilone plus capecitabine resulted in a median PFS of 4.4 months (95\% CI, 4.1 to 5.6 ) versus 2.8 months (95\% CI,
2.1 to 3.4) with capecitabine alone, and in a threefold increase of ORR (30\% vs. 10\%). These data suggest that ixabepilone combined with capecitabine may be effective for the treatment of various MBC patient populations with a poor prognosis and limited treatment options.

\section{Toxicity}

Ixabepilone is associated with a generally manageable safety profile. The toxicities associated with single-agent ixabepilone therapy are usually of a low grade and are comparable with those from other cytotoxic agents commonly used for breast cancer. In the four trials reported in the present review, the most common hematologic toxicity was myelosuppression, primarily neutropenia. Grade 3/4 neutropenia occurred in 53\% of patients resistant to taxanes and in $54 \%$ of those resistant to anthracyclines, taxanes, and capecitabine. Grade 3/4 leukopenia was observed in $2 \%$ of taxane-resistant patients and in $49 \%$ of taxane-resistant, anthracyclineresistant, and capecitabine-resistant patients. Febrile neutropenia was rare $[88,89]$. Similar to other microtubule inhibitors, neuropathy was one of the most frequent treatment-related adverse events occurring with ixabepilone. This was usually mild to moderate in severity and generally resolved after dose adjustments were made. Peripheral sensory neuropathy was the most frequent grade $3 / 4$ treatment-emergent adverse event (12 to $14 \%$ ). This toxicity was usually reversible, with resolution to grade 1 or baseline within a few weeks in the vast majority of patients. The frequency and severity of this toxicity with ixabepilone was comparable with that observed with other microtubule inhibitors (2 to $32 \%$ ) [96-99]. The combination of ixabepilone and capecitabine was well tolerated, with minimally overlapping toxicities. Apart from peripheral neuropathy, there was no worsening of capecitabine-associated toxicities (for example, hand-foot syndrome, fatigue, and vomiting) with the combination regimen.

\section{New drugs and the future of the treatment of metastatic breast cancer resistant to paclitaxel}

While ixabepilone is being evaluated in combination with other drugs, new drugs are currently being tested and have the potential to become standard treatments in this MBC setting. Albumin bound paclitaxel (nab-paclitaxel) has been studied in a phase II study of weekly albuminbound paclitaxel for patients with MBC heavily pretreated with taxanes. Response rates were $14 \%$ and $16 \%$ for the $100 \mathrm{mg} / \mathrm{m}^{2}$ and $125 \mathrm{mg} / \mathrm{m}^{2}$ cohorts, respectively; an additional $12 \%$ and $21 \%$ of patients, respectively, had stable disease with an acceptable toxicity profile [100].

Larotaxel is a semisynthetic taxoid that has shown preclinical and clinical activity against taxane-resistant 
$\mathrm{MBC}$, and has the ability to cross the blood-brain barrier. In a study of larotaxel in combination with trastuzumab in patients with HER2-positive MBC, $42.3 \%$ of confirmed partial responses were achieved with a manageable toxicity [101]. Another taxoid currently evaluated in taxane-resistant tumors is cabazitaxel. Although cabazitaxel has not been evaluated in breast cancer, results on a phase III prostate cancer are available [102].

Poly(ADP ribose) polymerase inhibitors are one group of drugs with great potential in resistant breast cancer, especially triple-negative and BRCA-deficient breast cancer. A phase II study of olaparib in confirmed BRCA1/ BRCA2 carriers with advanced refractory breast cancer showed an ORR of 38\% [103]. Other poly(ADP ribose) polymerase inhibitors being evaluated include veliparib in combination with temozolamide, results for which will be available in the near future [104].

\section{Conclusion}

Drug resistance (primary or acquired) is a leading cause of treatment failure in patients with cancer, especially MBC. Patients with advanced or MBC commonly develop disease resistance to chemotherapy and even biologic therapies such as trastuzumab, leaving few effective treatment options. The occurrence of MDR disease in many patients with advanced breast cancer due to the overexpression of $\beta I I I-t u b u l i n$ isotype or drug transporters, such as P-gp, demands new approaches. Consequently, there is a significant need for novel agents that are effective in drug-resistant tumors with mechanisms of action that are different from the available chemotherapeutics.

The epothilone B analog ixabepilone demonstrates significant antitumor activity against a variety of tumor cells with primary or acquired drug resistance, including MDR. Ixabepilone is less susceptible to the common mechanisms of drug resistance, particularly tubulin mutations, compared with taxanes and other traditional chemotherapy. Clinical trials demonstrate single-agent ixabepilone to be active in $\mathrm{MBC}$ patients with highly resistant or refractory disease who have a significant tumor burden. Antitumor activity was observed in those patients who have had extensive prior therapy with anthracyclines, taxanes, and/or capecitabine. Ixabepilone toxicity was manageable and comparable with other commonly used chemotherapeutics for MBC. In combination regimens, ixabepilone plus capecitabine resulted in greater activity compared with capecitabine alone in a taxane-resistant population, without significantly increasing toxicity. Ixabepilone has been approved by the US Food and Drug Administration for use in combination with capecitabine for the treatment of locally advanced breast cancer or MBC after the failure of an anthracycline and a taxane, and as monotherapy after the failure of an anthracycline, a taxane, and capecitabine. A previous publication suggests that the cost-effectiveness ratio could be higher for addition of ixabepilone to capecitabine treatment [105].

The potential of ixabepilone in patients with early-stage breast cancer is currently under evaluation. Given the clinical impact of drug resistance in breast cancer and other malignancies, new agents are clearly needed with differential sensitivity to the various mechanisms of tumor resistance compared with the standard chemotherapy drugs. Increased application of pharmacogenomics may also allow for the identification of patients with, or at increased risk for, drug resistance as well as those who are most likely to benefit from the treatment.

\begin{abstract}
Abbreviations
ABC, ATP-binding cassette; Cl, confidence interval; HER2, human epidermal growth factor receptor-2; MBC, metastatic breast cancer; MDR, multidrug resistance; MRP1, multidrug-resistant protein-1; ORR, overall response rate; PCR, polymerase chain reaction; PFS, progression-free survival; P-gp, P-glycoprotein; RT, reverse transcription.
\end{abstract}

\section{Acknowledgements}

This article is part of Breast Cancer Research Volume 12 Supplement 2: Advanced breast cancer therapy. The full contents of the supplement are available online at http://breast-cancer-research.com/supplements/12/S2. Publication of this supplement has been sponsored by Bristol Myers Squibb Company. Translation services and administrative support were provided to the authors by Thomson Reuters, Healthcare and Science.

Competing interests

The author receives research grants from Bristol Myers Squibb.

\section{Author details}

'The Methodist Hospital/Weill Cornell University, 6550 Fannin Street, SM701, Houston, TX 77030, USA. ${ }^{2}$ Department of Medical Oncology, Instituto Naciona de Enfermedades Neoplásicas, Av. Angamos Este 2520, Lima, Perú.

Published: 22 October 2010

\section{References}

1. O'Shaughnessy J: Extending survival with chemotherapy in metastatic breast cancer. Oncologist 2005, 10(Suppl 3):20-29.

2. NCCN Clinical Practice Guidelines in Oncology - Breast Cancer, v.2.2007 [http://www.ncen.org]

3. Cortes J, Baselga J: Targeting the microtubules in breast cancer beyond taxanes: the epothilones. Oncologist 2007, 12:271-280.

4. Gralow JR: Optimizing the treatment of metastatic breast cancer. Breast Cancer Res Treat 2005, 89(Suppl 1):S9-S15.

5. Gradishar WJ, Tjulandin S, Davidson N, Shaw H, Desai N, Bhar P, Hawkins M, O'Shaughnessy J: Phase III trial of nanoparticle albumin-bound paclitaxel compared with polyethylated castor oil-based paclitaxel in women with breast cancer. J Clin Oncol 2005, 23:7794-7803.

6. Porkka K, Blomqvist C, Rissanen P, Elomaa I, Pyrhönen S: Salvage therapies in women who fail to respond to first-line treatment with fluorouracil, epirubicin, and cyclophosphamide for advanced breast cancer. J Clin Oncol 1994, 12:1639-1647.

7. Giaccone G, Pinedo HM: Drug resistance. Oncologist 1996, 1:82-87.

8. Blum JL, Dieras V, Lo Russo PM, Horton J, Rutman O, Buzdar A, Osterwalder B: Multicenter, phase II study of capecitabine in taxane-pretreated metastatic breast carcinoma patients. Cancer 2001, 92:1759-1768.

9. Reichardt P, Von Minckwitz G, Thuss-Patience PC, Jonat W, Kölbl H, Jänicke F, Kieback DG, Kuhn W, Schindler AE, Mohrmann S, Kaufmann M, Lück HJ: Multicenter phase II study of oral capecitabine $\left(X_{\text {eloda }}{ }^{\circledR}\right)$ in patients with metastatic breast cancer relapsing after treatment with a taxanecontaining therapy. Ann Oncol 2003, 14:1227-1233.

10. Wist EA, Sommer HH, Ostenbad B, Risberg T, Bremnes Y, Mjaaland I: Oral 
capecitabine in anthracycline- and taxane-pretreated advanced/ metastatic breast cancer. Acta Oncol 2004, 43:186-189.

11. Lee JJ, Swain SM: Development of novel chemotherapeutic agents to evade the mechanisms of multidrug resistance (MDR). Semin Oncol 2005, 32:S22-\$26.

12. Seidman AD: Monotherapy options in the management of metastatic breast cancer. Semin Oncol 2003, 30:6-10.

13. Shigeoka Y, Itoh K, Igarishi T, Ishizawa K, Saeki T, Fujii H, Minami H, Imoto S, Sasaki Y: Clinical effect of irinotecan in advanced and metastatic breast cancer patients previously treated with doxorubicin- and docetaxelcontaining regimens. Jpn J Clin Oncol 2001, 31:370-374.

14. Degardin M, Bonneterre J, Hecquet B, Pion JM, Adenis A, Horner D, Demaille $A$ : Vinorelbine (navelbine) as a salvage treatment for advanced breast cancer. Ann Oncol 1994, 5:423-426.

15. Slammon DJ, Leyland-Jones B, Shak S, Fuchs H, Paton V, Bajamonde A Fleming T, Eiermann W, Wolter J, Pegram M, Baselga J, Norton L: Use of chemotherapy plus a monoclonal antibody against HER2 for metastatic breast cancer that overexpresses HER2. N Engl J Med 2001, 344:783-792.

16. Geyer CE, Forster J, Lindquist D, Chan S, Romieu CG, Pienkowski T, JagielloGruszfeld A, Crown J, Chan A, Kaufman B, Skarlos D, Campone M, Davidson N, Berger M, Olivia C, Rubin SD, Stein S, Cameron D: Lapatinib plus capecitabine for HER2-positive advanced breast cancer. N Engl J Med 2006 355:2733-2743.

17. Mariani G, Gianni L: Adjuvant trastuzumab in early breast cancer. Ann Oncol 2006, 17(Suppl 10):x54-x58.

18. Nahta R, Esteva FJ: HER2 therapy: molecular mechanisms of trastuzumab resistance. Breast Cancer Res 2006, 8:215.

19. Dean M, Fojo T, Bates S: Tumour stem cells and drug resistance. Nat Rev Cancer 2005, 5:275-84

20. Lynch MD, Cariati M, Purushotham AD: Breast cancer, stem cells and prospects for therapy. Breast Cancer Res 2006, 8:211.

21. Yagüe $E$, Arance A, Kubitza L, O'Hare M, Jat P, Oglivie CM, Hart IR, Higgins CF, Raguz S: Ability to acquire drug resistance arises early during the tumorigenesis process. Cancer Res 2007, 67:1130-1137.

22. Lee FY, Borzilleri R, Fairchild CR, Kim SH, Long BH, Reventos-Suarez C, Vite GD, Rose WC, Kramer RA: BMS-247550: a novel epothilone analog with a mode of action similar to paclitaxel but possessing superior antitumor efficacy. Clin Cancer Res 2001, 7:1429-1437.

23. Altmann KH, Wartmann M, O'Reilly T: Epothilones and related structures - a new class of microtubule inhibitors with potent in vivo antitumor activity. Biochim Biophys Acta 2000, 1470:M79-M91

24. Longley DB, Johnston PG: Molecular mechanisms of drug resistance. Pathol 2005, 205:275-292.

25. Leonessa F, Clarke R: ATP binding cassette transporters and drug resistance in breast cancer. Endocr Relat Cancer 2003, 10:43-73.

26. Trock BJ, Leonessa F, Clarke R: Multidrug resistance in breast cancer: a metaanalysis of MDR1/gp170 expression and its possible functional significance. J Natl Cancer Inst 1997, 89:917-931.

27. Larkin A, O-Driscoll L, Kennedt S, Purcell R, Moran E, Crown J, Parkinson M, Clynes M: Investigation of MRP-1 protein and MDR-1 P-glycoprotein expression in invasive breast cancer: a prognostic study. Int J Cancer 2004, 112:286-294.

28. Lizard-Nacol S, Genne P, Coudert B, Riedinger JM, Arnal M, Sancy C, BrunetLecomte P, Fargeot P: MDR1 and thymidylate synthase (TS) gene expressions in advanced breast cancer: relationships to drug exposure, p53 mutations, and clinical outcome of the patients. Anticancer Res 1999, 19:3575-3581.

29. Rudas M, Filipits M, Taucher S, Stranzl T, Steger GG, Jakesz R, Pirker R, Pohl G: Expression of MRP1, LRP and Pgp in breast carcinoma patients treated with preoperative chemotherapy. Breast Cancer Res Treat 2003, 81:149-157.

30. Tsukamoto F, Shiba E, Taguchi T, Sugimoto T, Watanabe T, Kim SJ, Tanji Y, Kimoto Y, Izukura M, Takai SI: Immunohistochemical detection of Pglycoprotein in breast cancer and its significance as a prognostic factor. Breast Cancer 1997, 4:259-263.

31. Burger H, Foekens JA, Look MP, Meijer-van Gelder ME, Klijn JG, Wierner EA, Stoter G, Nooter K: RNA expression of breast cancer resistance protein, lung resistance-related protein, multidrug resistance-associated proteins 1 and 2 , and multidrug resistance gene 1 in breast cancer: correlation with chemotherapeutic response. Clin Cancer Res 2003, 9:827-836.

32. Schneider J, Lucas R, Sánchez J, Ruibal A, Tejerina A, Martín M: Modulation of molecular marker expression by induction chemotherapy in locally advanced breast cancer: correlation with the response to therapy and the expression of MDR1 and LRP. Anticancer Res 2000, 20:4373-4377.

33. Borst $P$, Evers R, Kool M, Wijnholds J: A family of drug transporters: the multidrug resistance-associated proteins. J Nat Cancer Inst 2000, 92:1295-1302.

34. Filipits M, Pohl G, Rudas M, Dietze O, Las X, Grill R, Pirker R, Zielinski CC, Hausmaninger $H$, Kubista E, Samonigg $H$, Jakesz R: Clinical role of multidrug resistance protein 1 expression in chemotherapy resistance in early-stage breast cancer: the Austrian Breast and Colorectal Cancer Study Group. Clin Oncol 2005, 23:1161-1168

35. Doyle LA, Ross DD: Multidrug resistance mediated by the breast cancer resistance protein BCRP (ABCG2). Oncogene 2003, 22:7340-7358.

36. Bunting $\mathrm{KD}: \mathrm{ABC}$ transporters as phenotypic markers and functional regulators of stem cells. Stem Cells 2002, 20:11-20.

37. Staud F, Pavek P: Breast cancer resistance protein (BCRP/ABCG2). Int J Biochem Cell Biol 2005, 37:720-725.

38. Zhou J, Giannakakou P: Targeting microtubules for cancer chemotherapy. Curr Med Chem Anticancer Agents 2005, 5:65-71.

39. Drukman S, Kavallaris M: Microtubule alterations and resistance to tubulinbinding agents [review]. Int J Oncol 2002, 21:621-628.

40. Kavallaris M, Tait AS, Walsh BJ, He L, Horwitz SB, Norris MD, Haber M: Multiple microtubule alterations are associated with vinca alkaloid resistance in human leukemia cells. Cancer Res 2001, 61:5803-5809.

41. Wang Y, Cabral F: Paclitaxel resistance in cells with reduced $\beta$-tubulin. Biochim Biophys Acta 2005, 1744:245-255.

42. Kamath K, Wilson L, Cabral F, Jordan MA: $\beta$ III-tubulin induces paclitaxel resistance in association with reduced effects on microtubule dynamic instability. J Bio/ Chem 2005, 280:12902-12907.

43. Giannakakou P, Gussio R, Nogales E, Downing KH, Zaherevitz D, Bollbuck B, Poy G, Sackett D, Nicolaue KC, Fojo T: A common pharmacophore for epothilone and taxanes: molecular basis for drug resistance conferred by tubulin mutations in human cancer cells. Proc Natl Acad Sci U S A 2000, 97:2904-2909.

44. He L, Yang CP, Horwitz SB: Mutations in $\beta$-tubulin map to domains involved in regulation of microtubule stability in epothilone-resistant cell lines. $\mathrm{Mo}$ Cancer Ther 2001, 1:3-10.

45. Verills NM, Flemming CL, Liu M, Ivery MT, Cobon GS, Norris MD, Haber M, Kavallaris M: Microtubule alterations and mutations induced by desoxyepothilone B: implications for drug-target interactions. Chem Biol 2003, 10:597-607.

46. Zhangg CC, Yang JM, White E, Murphy M, Levine A, Hait WN: The role of MAP4 expression in the sensitivity to paclitaxel and resistance to vinca alkaloids in p53 mutant cells. Oncogene 1998, 16:1617-1624.

47. Rouzier R, Rajan R, Wagner P, Hess KR, Gold DL, Stec J, Ayers M, Ross JS, Zhang P, Bucholz TA, Kuerer H, Green M, Arun B, Hotobagyi GN, Symmans WF, Pusztai $\mathrm{L}$ : Microtubule-associated protein tau: a marker of paclitaxel sensitivity in breast cancer. Proc Natl Acad Sci U S A 2005, 102:8315-8320.

48. Dumontet C, Jaffrezou JP, Tsuchiya E, Duran GE, Chen G, Derry WB, Wilson L, Jordan MA, Sikic BI: Resistance to microtubule-targeted cytotoxins in a K562 leukemia cell variant associated with altered tubulin expression and polymerization. Bull Cancer 2004, 91:E81-E112.

49. Berrieman HK, Lind MJ, Cawkwell L: Do $\beta$-tubulin mutations have a role in resistance to chemotherapy? Lancet Oncol 2004, 5:158-164.

50. Paradiso A, Mangia A, Chiriatti A, Tommasi S, Zito A, Latorre A, Schittulli F, Lousso V: Biomarkers predictive for clinical efficacy of taxol-based chemotherapy in advanced breast cancer. Ann Oncol 2005, 16(Suppl 4):iv14-iv19.

51. Tomassi S, Mangia A, Lacalamita R, Bellizzi A, Fedele V, Chiriatti A, Thomssen C, Kendzierski N, Latorre A, Larusso V, Schittulli F, Zito F, Kavallaris M, Paradiso A: Cytoskeleton and paclitaxel sensitivity in breast cancer: the role of $\beta$ tubulins. Int J Cancer 2007, 120:2078-2085.

52. Mozetti S, Ferlini C, Concolino P, Filippetti F, Raspaglio G, Prislei S, Gallo D, Martinelli E, Ranelletti FO, Ferrandina G, Scambia G: Class III $\beta$-tubulin overexpression is a prominent mechanism of paclitaxel resistance in ovarian cancer patients. Clin Cancer Res 2005, 11:298-305.

53. Valkov NI, Sullivan DM: Drug resistance to DNA topoisomerase I and II inhibitors in human leukemia, lymphoma, and multiple myeloma. Semin Hematol 1997, 34:48-62

54. Lage H, Dietel M: Involvement of the DNA mismatch repair system in antineoplastic drug resistance. J Cancer Res Clin Oncol 1999, 125:156-165.

55. Fedier A, Schwarz VA, Walt $H$, Carpini RD, Haller U, Fink D: Resistance to 
topoisomerase poisons due to loss of DNA mismatch repair. Int $J$ Cancer 2001, 93:571-576.

56. Mackay HJ, Cameron D, Rahilly M, Mackean MJ, Paul L, Kaye SB, Brown R Reduced MLH1 expression in breast tumors after primary chemotherapy predicts disease-free survival. $J$ Clin Oncol 2000, 18:87-93.

57. Son BH, Ahn SH, Ko CD, Ka IW, Gong GY, Kim JC: Significance of mismatch repair protein expression in the chemotherapeutic response of sporadic invasive ductal carcinoma of the breast. Breast J 2004, 10:20-26.

58. Oudin C, Bonnetain F, Boidot R, Végran F, Soubeyrand MS, Arnould L, Riedinger JM, Lizard-Nacol S: Patterns of loss of heterozygosity in breast carcinoma during neoadjuvant chemotherapy. Int J Oncol 2007, 30:1145-1151.

59. O'Donovan N, Crown J, Stunell H, Hill AD, McDermott E, O'Higgins N, Duffy MJ: Caspase 3 in breast cancer. Clin Cancer Res 2003, 9:738-742.

60. Végran F, Boidot R, Oudin C, Riedinger JM, Bonnetain F, Lizard-Nacol S: Overexpression of caspase-3s splice variant in locally advanced breast carcinoma is associated with poor response to neoadjuvant chemotherapy. Clin Cancer Res 2006, 12:5794-5800.

61. O'Connor PM, Jackman J, Bae I, Myeres TG, Fan S, Mutoh M, Scudiero DA, Monks A, Sausville EA, Weinstein JN, Friend S, Fornace AR Jr, Kohn KW: Characterization of the $\mathrm{p} 53$ tumor suppressor pathway in cell lines of the National Cancer Institute anticancer drug screen and correlations with the growth-inhibitory potency of 123 anticancer agents. Cancer Res 1997, 57:4285-4300.

62. Aas T, Børresen AL, Geisler S, Smith-Søresnsen B, Jonsen H, Varhaug JE, Akslen LA, Lønning PE: Specific P53 mutations are associated with de novo resistance to doxorubicin in breast cancer patients. Nat Med 1996, 2:811-814.

63. Andersson J, Larsson L, Klaar S, Holmberg L, Nilsson J, Inganäs M, Carlsson G, Ohd J, Rudenstam CM, Gustavsson B, Bergh J: Worse survival for TP53 (p53)mutated breast cancer patients receiving adjuvant CMF. Ann Oncol 2005, 16:743-748.

64. Dumontet C, Sikic BI: Mechanisms of action of and resistance to antitubulin agents: microtubule dynamics, drug transport, and cell death. J Clin Oncol 1999, 17:1061-1070

65. Pandolfi PP: Breast cancer - loss of PTEN predicts resistance to treatment. N Engl J Med 2004, 351:2337-2338.

66. Brown I, Shalli K, McDonald SL, Moir SE, Hutcheon AW, Heys SD, Schofield AC: Reduced expression of p27 is a novel mechanism of docetaxel resistance in breast cancer cells. Breast Cancer Res 2004, 6:R601-R607.

67. Sládek NE, Kollander R, Sreerama L, Kiang DT: Cellular levels of aldehyde dehydrogenases (ALDH1A1 and ALDH3A1) as predictors of therapeutic responses to cyclophosphamide-based chemotherapy of breast cancer: a retrospective study. Rational individualization of oxazaphosphorinebased cancer chemotherapeutic regimens. Cancer Chemother Pharmacol 2002, 49:309-321

68. DeGregorio MW, Perez EA: Molecular mechanisms of drug resistance. In Cecil Textbook of Medicine. Edited by Bennett JC, Plum F. Philadelphia, PA: W.B. Saunders Company; 1996:1056-1060.

69. Bedard PL, Di Leo A, Piccart-Gebhart M: Taxanes: optimizing adjuvant chemotherapy for early-stage breast cancer. Nat Rev Clin Oncol 2010, 7:22-36.

70. Miwa M, Ura M, Nishida M, Sawada N, Ishikawa T, Mori K, Shimma N, Umeda I, Ishitsuka: Design of a novel oral fluoropyrimidine carbamate, capecitabine, which generates 5 -fluorouracil selectively in tumors by enzymes concentrated in human liver and cancer tissues. Eur J Cancer 1998, 34:1274-1281.

71. Blum JL, Jones SE, Buzdar AU: Multicenter phase II study of capecitabine in paclitaxel-refractory metastatic breast cancer. J Clin Oncol 1999, 17:485-493.

72. Bollag DM, McQuenney PA, Zhi J, Hensens O, Koupal L, Liesch J, Goetz M, Lazarides E, Woods CM: Epothilones, a new class of microtubule-stabilizing agents with a taxol-like mechanism of action. Cancer Res 1995 55:2325-2333.

73. Gerth K, Berforf N, Höfle G, Irschik H, Reichenbach H: Epothilons A and B: antifungal and cytotoxic compounds from Sorangium cellulosum (Myxobacteria). Production, physico-chemical and biological properties. J Antibiot (Tokyo) 1996, 49:560-563.

74. Nogales E, Wolf SG, Khan IA, Ludeña RF, Downing KH: Structure of tubulin at 6.5 A and location of the taxol-binding site. Nature 1995, 375:424-427.

75. Bode CJ, Gupta ML Jr, Reiff EA, Suprenant KA, Georg Gl, Himes RH: Epothilone and paclitaxel: unexpected differences in promoting the assembly and stabilization of yeast microtubules. Biochemistry 2002, 41:3870-3874

76. Nettles JH, Li K, Cornett B, Krahn JM, Snyder JP, Downing KH: The binding mode of epothilone $A$ on $a, \beta$-tubulin by electron crystallography. Science 2004, 305:866-869.

77. Kolman A: Activity of epothilones. Curr Opin Investig Drugs 2005, 6:616-622.

78. Jordan MA, Miller H, Ray A: The Pat-21 breast cancer model derived from a patient with primary $\operatorname{Taxol}^{\circledast}$ resistance recapitulates the phenotype of its origin, has altered $\beta$-tubulin expression and is sensitive to ixabepilone [abstract LB-280]. Proc Am Assoc Cancer Res 2006, 47:73.

79. Lee FY, Camuso A, Castenada S, Fager K, Flefleh C, Inigo I, Johnson K, Kan D, McGlinchey K, Peterson R, Smykla S, Wen ML< Fairchild C, Kramer R: Preclinical studies of ixabepilone (BMS-247550) demonstrate optimal antitumor activity against both chemotherapy-sensitive and -resistant tumor types. Proc Am Assoc Cancer Res 2006, 47:Abstract 503.

80. Pivot $X$, Dufresne A, Villanueva C: Efficacy and safety of ixabepilone, a novel epothilone analogue. Clin Breast Cancer 2007, 7:543-549.

81. Long BH, Wang L, Lorica A, Wang RC, Brattain MG, Casazza AM: Mechanisms of resistance to etoposide and teniposide in acquired resistant human colon and lung carcinoma cell lines. Cancer Res 1991, 51:5275-5283.

82. Giannakakou P, Sackett DL, Kang YK, Zhan Z, Buters JT, Fojo T, Poruchynsky MS: Paclitaxel-resistant human ovarian cancer cells have mutant $\beta$ tubulins that exhibit impaired paclitaxel-driven polymerization. J Biol Chem 1997, 272:17118-17125.

83. Wartmann M, Altmann $\mathrm{KH}$ : The biology and medicinal chemistry of epothilones. Curr Med Chem Anticancer Agents 2002, 2:123-148.

84. Vansteenkiste J, Lara PN Jr, Le Chevalier T, Breton JL, Bonomi P, Sandler AB, Socinski MA, Delbaldo C, McHenry B, Lebwohl D, Peck R, Edelman MJ: Phase II clinical trial of the epothilone B analog, ixabepilone, in patients with non-small-cell lung cancer whose tumors have failed first-line platinumbased chemotherapy. J Clin Oncol 2007, 25:3448-3455.

85. Fojo AT, Menefee M, Poruchynsky MS: A translational study of ixabepilone (BMS-247550) in renal cell cancer (RCC): assessment of its activity and demonstration of target engagement in tumor cells [abstract 4541]. J Clin Oncol 2005, 23:388S.

86. Whitehead RP, McCoy S, Rivkin SE, Gross HM, Conrad ME, Doolittle GC, Wolff RA, Goodwin JW, Dakhill SR, Abbruzzese JL: A phase II trial of epothilone B analogue BMS-247550 (NSC \#710428) ixabepilone, in patients with advanced pancreas cancer: a Southwest Oncology Group study. Invest New Drugs 2006, 24:515-520.

87. McDaid HM, Mani S, Shen HJ, Muggia F, Sonnichsen D, Horwitz SB: Validation of the pharmacodynamics of BMS-247550, an analogue of epothilone B, during a phase I clinical study. Clin Cancer Res 2002, 8:2035-2043.

88. Thomas E, Taberon J, Fornier M, Conté P, Furnoleau P, Lluch A, Vahdat LT, Bunnell Cam Burris HA, Viens P, Baselga J, Rivera E, Guarneri V, Poulart V, Klimovsky J, Levwohl D, Martin M: Phase II clinical trial of ixabepilone (BMS-247550), an epothilone B analog, in patients with taxane-resistant metastatic breast cancer. J Clin Oncol 2007, 25:3399-3406.

89. Perez EA, Lerzo G, Pivot X, Thomas E, Vahdat L, Bossserman L, Viens P, Cai C, Mullaney B, Peck R, Hortobagyi GN: Efficacy and safety of ixabepilone (BMS-247550) in a phase II study of patients with advanced breast cancer resistant to an anthracycline, a taxane, and capecitabine. J Clin Oncol 2007, 25:3407-3414.

90. Bunnel C, Vahdat L, Schwatzberg L, Gralow J, Klimovsky J, Poulart V, Peck R, Thomas E: Phase I/II study of ixabepilone plus capecitabine in anthracycline-pretreated/resistant and taxane-resistant metastatic breast cancer. Clin Breast Cancer 2008, 8:234-241.

91. Cleator S, Heller W, Coombes RC: Triple-negative breast cancer: therapeutic options. Lancet Oncol 2007, 8:235-244.

92. Thomas E: Ixabepilone plus capecitabine for metastatic breast cancer progressing after anthracycline and taxane treatment. J Clin Oncol 2007, 25:5210-5217.

93. Lerzo GL: Phase III study of ixabepilone plus capecitabine in metastatic breast cancer (MBC) progressing after anthracyclines and taxanes: subgroup analysis in HER2+ disease [abstract 151]. In ASCO Annual Meeting Proceedings. 8 September 2007; San Francisco.

94. Moulder S, Li H, Wang M, Gradishar WJ, Perez EA, Sparano JA, Pins M, Yang X, Sledge GW: A phase II trial of trastuzumab plus weekly ixabepilone and carboplatin in patients with HER2-positive metastatic breast cancer: an Eastern Cooperative Oncology Group Trial. Breast Cancer Res Treat 2010, 119:663-671.

95. Picot XB, Lee RK, Tomas ES, Chung H, Fein LE, Chan VF, Jassem J, Hurtado de 
Mendoza F, Mukhopadhyay P, Roché HH: Phase III study of ixabepilone plus capecitabine in patients with metastatic breast cancer (MBC) resistant to anthracyclines/taxanes: subgroup analysis by estrogen receptor (ER) status [abstract \#221]. In ASCO Annual Meeting Proceedings. 8 September 2007; San Francisco.

96. Nabholtz JM, Gelmon K, Bontenbal M, Spielmann M, Catimel G, Conte P, Klaassen U, Namer M, Bonneterre J, Furnoleau P, Winograd B: Multicenter, randomized comparative study of two doses of paclitaxel in patients with metastatic breast cancer. J Clin Oncol 1996, 14:1858-1867.

97. Winer EP, Berry DA, Woolf S, Duggan D, Kodnblith A, Harris LN, Michaelson RA, Kirshnew JA, Fleming GF, Perry MC, Graham ML, Sharp SA, Keresztes R, Henderson IC, Hudis C, Muss H, Norton L: Failure of higher-dose paclitaxel to improve outcome in patients with metastatic breast cancer: Cancer and Leukemia Group B Trial 9342. J Clin Oncol 2004, 22:2061-2068.

98. Jones SE, Erban J, Overmoyer B, Budd GT, Hutchins L, Lower E, Laufman L, Sundaram S, Urba WJ, Pritchard KI, Mennel R, Richards D, Olsen S, Meyers ML, Ravdin PM: Randomized phase III study of docetaxel compared with paclitaxel in metastatic breast cancer. J Clin Oncol 2005, 23:5542-5551.

99. Lee JJ, Swain SM: Peripheral neuropathy induced by microtubulestabilizing agents. J Clin Oncol 2006, 24:1633-1642.

100. Blum JL, Savin MA, Edelman G: Phase Il study of weekly albumin-bound paclitaxel for patients with metastatic breast cancer heavily pretreated with taxanes. Clin Breast Cancer 2007, 7:850-856.

101. Dieras V, Viens P, Veyret C, Romieur G, Awada A, LidbrinkW, Bonnefoi H, MeryMignard D, Dalenc F, Roché H: Larotaxel (L) in combination with trastuzumab in patients with HER2 + metastatic breast cancer (MBC): interim analysis of an open phase II label study [abstract 1070]. In ASCO Annual Meeting Proceedings. 30 May-3 June 2008; Chicago.

102. Sartor AO, Oudard S, Ozguroglue M, Hansen S, Machiels JHm Shen L, Gupta S, De Bono JS: Cabazitaxel or mitoxantrone with prednisone in patients with metastatic castration-resistant prostate cancer (mCRPC) previously treated with docetaxel: final results of a multinational phase III trial (TROPIC) [abstract 9]. In ASCO Annual Meeting Proceedings. 4-8 June 2010; Chicago.

103. Tutt A, Robson M, Garber JE, Domchek S, Audeh MW, Weitzel JN, Friedlander $M$, Carmichael J: Phase II trial of the oral PARP inhibitor olaparib in BRCAdeficient advanced breast cancer [abstract CRA501]. In ASCO Annual Meeting Proceedings. 29 May-2 June 2009; Orlando.

104. Isakoff SJ, Overmoyer B, Tung NM, Gelman RS, Giranda VL, Bernhard KM, Habin KR, Ellisen LW, Winer EP, Goss PE: A phase II trial of the PARP inhibitor veliparib (ABT888) and temozolomide for metastatic breast cancer [abstract 1019]. In ASCO Annual Meeting Proceedings. 4-8 June 2010; Chicago.

105. Reed SD, Li Y, Anstrom KJ, Schulman KA: Cost effectiveness of ixabepilone plus capecitabine for metastatic breast cancer progressing after anthracycline and taxane treatment. J Clin Oncol 2009, 27:2185-2191.

doi:10.1186/bcr2573

Cite this article as: Rivera $\mathrm{E}, \mathrm{Gomez} \mathrm{H}$ : Chemotherapy resistance in metastatic breast cancer: the evolving role of ixabepilone. Breast Cancer Research 2010, 12(Suppl 2):S2. 